\title{
ON PURCHASING A HOME COMPUTER
}

\author{
Hannu Lahtinen \\ University of Tampere, Finland.
}

Key words: Home computers, needs, models, decision-making.

\begin{abstract}
The number of computers at home is continuously growing. To this end it is important to know more about the purchasing process. In this study we shall describe how some Finnish families purchased their home computer. We interviewed more than 90 families who had just purchased a home computer and also some non-computer families. Men and children seem to take the initiative in a family during the purchasing process. Especially when a family is purchasing their first home computer, they very often turn to their experienced friends for help. From this point of view home computers mostly differ from other durable goods in a family. Because of the possibility to use experience accumulated in the net of friends, the purchases of various families differ much less than we supposed before this study. The most important reason for purchasing a home computer was that adults would keep up with technical development. Generally families prepare more for the future than for this day by buying a home computer. When speaking about the directions of diffusion, the inputs that come from outside a family are most important. The outcome of the most recent interviews was that in future the Internet will get more tasks for home computers, but for the present we can find more potential expectations than applications in use.
\end{abstract}

\section{INTRODUCTION}

This paper reports on purchasing a home computer from a standpoint of a family. On the following pages a home computer does not only mean hardware but also software and all accessories connected with it. They are durable goods that, in principal, every member of a family has the possibility to use at home. A family, in our context, means a group of people (at least one) who live at the same address. corrected. The Erratum to this chapter is available at DOI: 10.1007/978-0-387-35511-5_17 
The interviews behind this study have been made over the time between 1996-1999. In this interval the families in Finland have been recovered from an economic crisis (1991-1994 at its worst). The statistics show that on the average the families have had more money than before, but for instance because of unemployment the resources have been unevenly divided. From the standpoint of this study it is also very remarkable that the state authorities have signalled favourable atmosphere for purchasing a home computer. An impulsive starting shot in the beginning of 1995 was the report: "Finland to information society - national outlines." They began to speak about computer literacy as a new ability. One of the concrete aims was to teach computer literacy to every child at school.

Statistics show that in 1997 there was in Finland on the average 1,2 computers per a family. But still $64 \%$ of the households do not have any home computer. More than $50 \%$ of these households having a home computer, intend to buy a new microcomputer in this or next year. More than $70 \%$ of the households with no home computer do not have any intention to buy one. For the sake of comparison the same statistics show that there is on average 0,6 mobile phones per household [10].

In this study the main question is: What are the factors that explain the behaviour of families, when they are going to purchase a home computer. At first we present some observations of families regarding the whole process. At the second phase, the analysis will especially focus to the very beginning of the whole process. In addition there are some observations about the buying behaviour of families, and how they succeeded getting started with their new home computer.

We gathered the raw data of this study by using open questions in interviews of individual families and groups of pupils within the interval autumn 1996 - spring 1999. The pupils belong to the upper level of a comprehensive school and higher secondary school. Most of the data gathering was carried out in such a way that one member of the family wrote their story. In the end of data gathering there was a focusing interview containing also some structured questions. Fourteen families took part in the focusing interviews. The whole was based on the experiences of 92 families. In choosing the families we have tried to achieve a good representation across ordinary Finnish families. There are also 8 families that do not have a home computer.

We analysed these stories by using the grounded theory (GT) [11]. The grounded theory approach is a qualitative research method and its basic tenet is that a new tentative theory must be grounded in the data. In the analysis we systematically tried to find similar or different concepts or categories from the data. In practice the work was inductively proceeding from details 
to generalisations. In this paper, to facilitate reading we report on main observations in the opposite direction.

\section{PURCHASING A HOME COMPUTER AS THE DECISION SITUATION OF A FAMILY}

In order to give an overall picture of a purchasing process we first present some "parameters" of the whole process: what kind of happenings the families remember during the process, how long does it take to purchase, and how it can be compared with the purchasing process of other durable goods by the family.

The overall view of purchasing a home computer varied from an exciting task to "dry bun". Families mainly experienced it as an uncomfortable and troublesome task. Three main problems emerged:

- decision-making and selection from many alternatives

- to get reliable information

- the rapid development of hardware and software

After all these difficulties it is very important and comforting that almost all the families were afterwards satisfied with their decisions.

The duration of a purchase from the first discussions to the decision varied from some hours to one year. The average time is $2-3$ months. On the grounds of the data collected in this study the length does not systematically depend on how many computers the family have purchased. To purchase a home computer takes about twice as much time as purchasing a car [1]. This is remarkable, because in Finland a car costs more than ten times more than a home computer.

It is typical to the process that the activity in the families increases when the process goes to the end. Typically men and children act as principal actors. However, the latest interviews indicated that women are activating, and, concerning the use of the Internet, the difference between boys and girls has become smaller. Also in purchasing a car men play a leading role although a difference in use has diminished to an equal level among male and female drivers in the course of years.

One possibility to describe the purchase of a home computer is to compare it with other durable goods at home. On that account the families were asked to compare their experiences. The distinct tendency was that most people have felt that, for example, buying a television is a much simpler task than buying a home computer. From the data we found out especially:

- only few members of a family are devoted to the project 
- providing for the future because the development of software and hardware is moving very fast

- a black box problem-a family does not know, what they are exactly buying

- faults in products, especially in CD -stations

- families are afraid to be swindled when they close a deal

Sometimes from the purchase of other household appliances families may get support, but for the purchase on a home computer the threshold is much higher than other purchases. This also very often leads into other kinds of behaviour. The biggest difference is that in practice all families ask their friends to help, when they are going to buy a home computer. In our sample there are many families that participated in the process only as the role of payer.

"I use an expert, I trust him, I took a thing as a joke. When purchasing a television, I shall understand it something. Here I took part in as a blind."

As a summary we can say that in complexity the purchase of a home computer belongs to the most demanding quarter of the purchases of household appliances. We found that purchasing a home computer demands more up-to-date information and also conjectures about the future development. As a whole we can describe a purchase of most families as a process, that contains the four steps we can see in Figure 1.

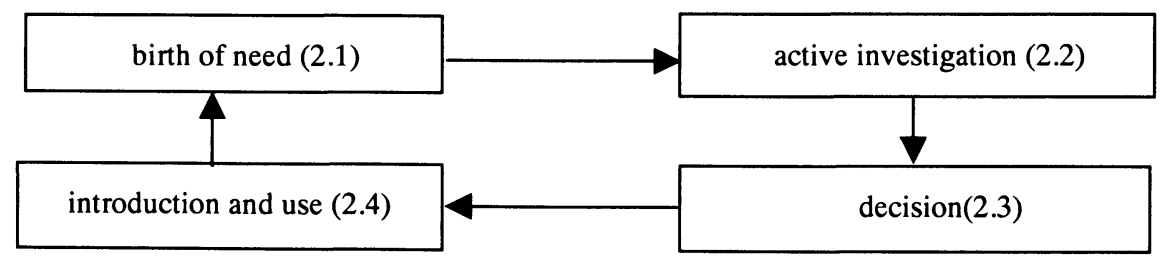

Figure 1. A stage model of purchasing a home computer

The phasing in Figure 1 better describes a reality when the family itself takes part in the whole process. We must do at least semantic changes in the Figure 1, if some persons outside the family strongly dominate a purchase process. In that case active investigation resembles more the commission of a consultant than the family's own study. In that case we can speak about one kind of outsourcing in the scale of a family [9]. If at least one member of the family follows the IT development all the time, then the active investigation does not so strongly cumulate before the decision step. According to our observations this is however quite exceptional. If an employer has offered a 
computer to a family, then it is a totally different story. In this study two families got a computer from the father's employer.

In the next sections we shall separately consider every step in Figure 1. We shall lay stress on the birth of need step because it plays the gatekeeper role to the start of the whole process.

\subsection{Birth of need}

One main goal of this study is to answer the questions: Why and how does a family begin to think about the purchase of a home computer. Without doubt there are many individual factors behind the process and further there may also be the interdependent chains of causal connections. From the data gathered we found that it is typical that before the birth of need step some change took place in the inside or outside conditions of a family.

The motives developed in a family are often connected with the moments that are the result of a lapse of time in the stage of a family, typically the growth of children, changes in working environment, retirement and so on. From the data we found some events or states that have given a reason for a family to kindle purchasing a home computer:

- growth of the utilisation rate of a home computer, because the family can or wants to use a home computer more than before

- anticipate the variation of job in the workplace

- changes in "control groups" especially when the friends of the children got new games

- changes in the thresholds of purchasing especially as special offers for certain groups

- changes in software and hardware especially when installing new software in old hardware

These things can at the acute moment accumulate to motivate purchasing. This is linked with the question, why a family decided to purchase a home computer. When it was the question of the first home computer in a family, the following four motives showed up:

- games, entertainment

- to use a home computer for educational purposes

- study of the use of a computer, to keep up with technical development

- the standpoint of livelihood

Many families gave several alternative reasons for their decision. Nearly all of them said at least as ulterior motive that they wanted to keep up with technical development. When children are enthusiastic over playing games, it is at least in the payer's mind. There is often an individual or a little group in family that is clearly more active than other members of a family. When 
children acts as initiator of the purchase, entertainment and useful use are fairly important, but for adult people entertainment is of less importance.

When a family is going to purchase another home computer, the following reasons came out:

- new software demands more effective hardware

- the growing use in a family demands additional home computer(s)

- compatibility with software at working, studying and other places

- hardware got broken quickly

Both the main reasons and the initiators for the purchase stay quite unchanged from one purchase to another in the same family. In recent interviews the most important motive for purchasing a home computer was that adults wanted to keep up with technical development. The family gave many reasons why they have purchased several home computers. We can compare the motives mentioned before with the new study made in the USA [8]. It is based on interviews during the first three months of 1999 with some 30000 households. There the reasons for buying a PC were: a home-based business (14 percent), educational purposes (for adults 12 percent and children 11 percent), Web research (nearly 10 percent) and games (only 6 percent). Compared with Finland the most important difference is a homebased business. By this study in Finland business is very seldom the main reason to purchase a home computer. A difference in Web research is explained by a difference in the moments of data collection.

It is very difficult to describe the dynamics behind the birth of need because nearly everything that is linked with it is in continuous movement in time. In Figure 2 we try to describe the birth of need by an interaction between two states in a family. At any moment we can quite accurately identify the present state of a family and a little inaccurately a target state of a family. The latter is one kind of dream about how the things should be in the future. The birth of need will break up when the family identifies the sufficiently big difference between the two states. Before it the target state is more virtual because a family can not distinguish it from the present state.

Because of a rainbow dynamic in Figure 2-dreams can run away-it has points of contact with the most interviews gathered in this study. In Figure 1 the active investigation and decision steps are the operations that help the family to reach the goal. 


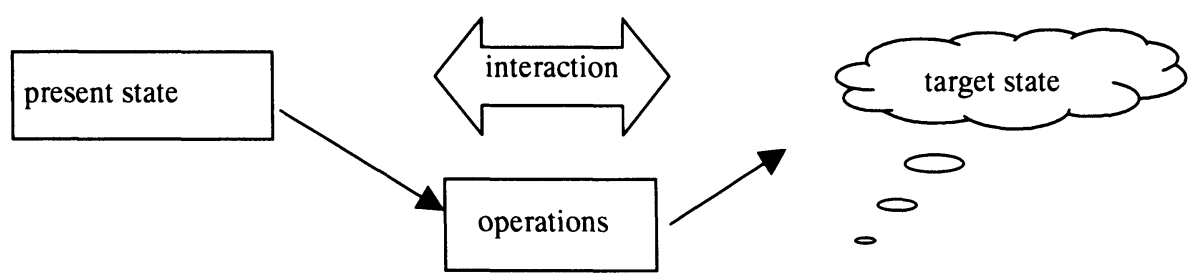

Figure 2. A state sketch of the birth of need

In this study we observe the purchase of a home computer from the standpoint of the ordinary family, but we can look at the question from many other aspects, too. Dhebar [5], for example, examined benefits and costs of a home computer. He very understandably explained why families are not ready to buy a new home computer soon after the previous acquisition. Based on interviews in practice it is, however, very difficult to calculate income that a family will get by purchasing a home computer. Assael [2]. has looked at the birth of need generally from the marketing side. He has introduced many internal and external input variables: consumer's past experiences, consumer characteristics, consumer motives, environmental influences and marketing stimuli

\subsubsection{Directions of diffusion connected with the birth of need}

In practice, the target state of the family describes many factors inside and outside of the family. Here we try to identify the directions of diffusion of enthusiasm and information.

In a family, it is typical that children infect a father with their enthusiasm. The dynamism connected with the series of events is very similar as in bigger organisations. For example, Damsgaard and Scheepers [3] describe in their report:

"Technology champions seek to 'get the attention' of the innovation from other, more powerful, actors in the organisation."

Generally flows of diffusion in a family are weaker and more obscure than we beforehand believed. For instance, the purchased home computer will not at all assure that an enthusiasm will be infectious to all the members in family. After many years there can be persons in a family, who did not touch the home computer. 
On the other hand between a family and its surroundings we can find many marks of flows or diffusion. When children's friends receive a novelty, it starts up dialogue in a family on necessity to receive the similar or better software and hardware home. This is known as flow down phenomenon, where a new innovation flows from the higher social group to lower one.

Outside a family for adults we can find the most important reference group from workplaces or study surroundings. People there meet each other and get ideas to why a home computer would be useful for their family. They can then take the necessary steps to 'sell' their ideas to the whole family. Especially in the early years of a computer many employees got ideas how to use a computer at workplace, but they had no possibilities to get a computer at their disposal. So they purchased a home computer to study and to use at home.

\subsubsection{Why did not a family purchase a home computer?}

According to our material a general reason to purchase a home computer demands a clear motive. There was three main answers to the 'why not' question:

- families believe that they have only a little to do with a home computer

- for economic reasons

- they feel certain uncertainty to use a computer

The latest reason is interesting because the same basic reason-uncertainty in using computers-can lead to opposite behaviour on various occasions. However, most families have a clear understanding of what they should do if, in spite of all, they purchase a home computer-they will turn to their experienced friends. One result of this study is that difficulties connected with a purchasing process do not explain these families' behaviour.

If we want to know what kind of stress due to the development of an information society has arisen, it is useful to listen to the families without computers, because it will quite soon be the time, when it demands more civil courage to be without a home computer than to buy one.

\subsection{Active investigation}

When the birth of need rises over the threshold of a family, the family will begin preparations for decision. It is typical for this stage to seek after information about appliances, products, shops, finance and so on. The stage of active investigation is important, because during this stage a family will identify certain selection rules to direct their final decision. When families collect information about home computers they normally use some kind of the elimination principle. In brief, they are mainly interested in appliances 
and potential shops, while the families in our study were not much interested in software

The minor interest in software is due to the fact that families think very little, where they actually will use a home computer before they buy it. Besides families feel that the risk of failure is low because of unofficial software.

When it is question of appliances families strongly focus their interest on new PC computers. There is a certain kind of mass effect that has an influence already during the state of active investigation. Because most friends, workplaces, study places, sellers and so on are attached by PC, it is quite understandable that families simplify their difficult task by eliminating unusual solutions already at an early stage.

The typical number of the source of information is two. Three sources of information that came out more than others are friends, computer journals and vendors. Friends are noticeably the most important, and friends and computer journals are about at the equal level.

Only $2 \%$ of the families have especially used the Internet for investigation, but it is going up quickly. When purchasing a home computer there are two strategic outlines: a family trusts its own ability to solve the problem or they trust the experiences of their friends. We can see this tendency also during the stage of active investigation. If the family is strongly binding to purchase a home computer, they very often begin the process by reading computer journals and after it they will talk with friends and vendors about the methods of selection. If we consider the successive purchases of the same family, we can see that the independence of families grows from one purchase to another. Perhaps the point is that when the experience of families is growing step by step they can better than before answer to the question: What is a home computer and what they can use it for? In other words, the target state in Figure 2 is more explicit than before and families have learned by using feedback.

How much the families will learn depends on what kind of intensity they ask help from their friends. The roles of friends can vary from an advisor to a buyer. Many families feel that to purchase a home computer is so solitary and involved a business that it's not worth them to highly devote their time and resources. From the interviews it came out that only few families (15\%) try to get the latest news of the development of home computers all the time. It was also surprising that families felt that they can only very little use their previous experiences. This feeling was mostly based on the quick development of computers, but it seems that the degree of difficulty grows from the growing experiences of families, too. 


\subsection{Decision-making}

During the stage of active investigation families will organise their perceptions to get the general idea of the situation and different alternatives. Normally it takes a lot of time and very often a family is tired of living in uncertainty and wants to make decision very soon. On this borderline a chance often influences the details of the decision. What happened to be in the vendor's storeroom may, for example, be a decisive factor. The decision to buy a home computer is generated by the decision of hardware, shops, and software mostly in this order.

Already at the stage of active investigation we saw that families were not interested in software. Families often know what kind of software there is on the market, but they are not nearly ready to invest in software. Within the latest purchases they $(n=13)$ have purchased software as follows:

- 7 practically nothing

- 6 only the operating system (WIN95/WIN98)

- 9 the operating system and some integrated software (MS OFFICE or part of it, MS WORKS )

Especially home computers purchased for playing games are not with software. the foregoing is parallel with the estimate of the Business Software Alliance [4]. They have calculated that about $38 \%$ of programs used in Finland are without license. If we follow the successive purchases of the same families, we can see that desire to buy or not to buy programs is the typical feature of the family. For instance, among the first seven above there are three families, which have purchased their first home computer. It seems, however, that when families are going to use their home computers to get financial benefits they use official programs, too. To use a home computer mainly for experiments there are many kinds of programs on the market. On the reverse of the coin is the fact that one traditional step of marketing is to get a consumer to experiment a product for sale.

The hardware of purchased computers becomes uniform year after year and follows quite near the top of development. The delay time of diffusion from the publication of an innovation to the introduction of families is becoming shorter day after day. The computers that employers have offered are, perhaps, not technically the latest fashion, but their software is superior to a normal home computer. One kind of unwritten law is that the home computer to be purchased must be better than adviser's own home computer. Two families only purchased their home computer as second-hand.

The diffusion of communications is fastest. In 1996 there were no mentions of the Internet, but after 1997 there is an increasing number of mentions of the Internet and as a peak there was one ISDN connection. 
Almost every family at least theoretically has an opportunity to buy a modem and telephone lines to connect their own computer to the Internet.

In our sample there are two strategic alternative ways to choose a shop. Some families decide on a new shop every time according to prevailing conditions while other families faithfully use the same shop every time. There are several examples of families who have changed the shop until they have been satisfied with the service. In the long term the use of the same shop is based on reciprocal trust between a vendor and a buyer. It takes a long time to build this mutual understanding, but there are some examples of events when one swindle has positively at once broken this trust. Almost all the home computers in this study have purchased from the shops whose main task is to sell computers. When purchasing a car for a family the parents more and more participate in a final state together for the decision. It seems that when purchasing a home computer the development is nearly opposite.

\subsection{Introduction and use}

Here we shall shortly tell how families succeeded with their new 'member' of the family. Only some families told that they have beforehand repaired possible problems in introduction and use. Usually they have aspired to ensure that the shop and/or some experts are available. In general the families have managed their new home computer surprisingly well. However, the help of friends and sales persons was very important. The most difficulties have happened soon after the computer has moved to home, because some devices have broken.

Most families are satisfied with their decisions. The clear disappointments have happened when a home computer for playing games has become 'old' too quickly or the purchase happened just before a new publication when prices tend to go down.

Also the original plans for the use of a home computer have predominantly come true. In many families, however, in the long term the focus of the use of a home computer has gradually changed. For instance, there are many computers purchased for playing games that have changed to a tool for children's homework. Sometimes the original plan has turned to the inverse direction, i.e. the computers purchased as a parent's tool have in practice changed to children's toys.

In many families a home computer has formed an active hobby at least for one member of the family. Then a home computer has changed their everyday life and they feel that they cannot live without it. However, in the majority of families a home computer has not after the first enthusiasm 
disturbed their everyday lives. They feel that the purpose of a home computer is only one more hobby with others.

It seems that in purchasing of a home computer the network of friends very effectively acts but the power of the same network is much smaller when we pay attention to the use of a home computer. Before, we mentioned that men and children most use home computers in a family. One reason for this may be one kind of change resistance. In the same way as in the large organisations we can try to decrease change resistance by taking the whole family with the process from the very beginning.

In interviews we asked families to give advice for those families that are planning to purchase a home computer. The most common advice was to ask for help of the experienced friends.

\section{CONCLUSION}

This study represents one kind of basic description that rather generates hypotheses than proves them. The method used and the findings derived in this study are strongly based on the empirical data that is direct linked to the selection of interviewees. Therefore the findings of this study represent the families that have happened to interact with it. The findings of this study are, however, in the majority of instances parallel to the findings of other studies from the same period.

About 15 years ago Dutton, Kovaric and Steinfield [7] in their paper asked: "What actually happens to a personal computer after a family purchases one. Does it entertain in the living room, facilitate work in the study, or gather dust in the closet?" We can now carefully answer that all alternatives are right and the Internet is bringing added value to the use of home computers. After, for example, the previous paper shows, that the development of home computers has not been so dramatic, than it seems on the outside.

The networks of friends balances information and experience needed for purchasing a home computer. It is one kind of neighbourly help that has been born anew. We can differentiate the families who have purchased from those that have not purchased a home computer from the order of their reasoning. The owners very often start the process by buying and after that they will think what they can really do with it, while the families without home computers start the process in reverse order. If we want get these families to buy computers, we must, in marketing methods, emphasise tasks to be performed with a home computer more than the apparatus itself.

In their paper Dutta and Segew [6] wrote: "A country such as Finland boasts of the highest penetration of the Internet in society among all 
countries in the world." Perhaps, but the results of this study show that it is still a long way to the productive use of home computers. However, there are many families that have by the meihod of learning-by-doing grown from novices to experts, who can now help their neighbours, too. For them a computer has settled from its base to the level of the everyday vehicle. Most families have also learned to understand, that the armaments race with devices is not worth it.

\section{REFERENCES}

[1] Alarautalammi J (1998), Perheen päätöksenteko auton hankinnassa (Decision-making of a family when purchasing a car), University of Helsinki.

[2] Assael, H (1995) Consumer Behaviour and Marketing Action, 5. edition, International Thompson Publishing, Cincinnati, Ohio. p. 83

[3] Damsgaard J and R. Scheepers (1999), A stage model of intranet technology implementation and management, In Pries-Heje, Ciborra, Kautz, Valor, Christiaanse, Avison and Heje (Eds.), Proceedings of the $7^{\text {th }}$ European Conference on Information Systems, Copenhagen Business School, Copenhagen, Denmark 23-25 June 1999, 100-116.

[4] BSA (1998), Business Software Alliancen - Suomi-Finland, [WWW-document] http://www.bsa.org/suomi/240998.html (15.12.1999)

[5] Dhebar A. (1996), Speeding high-tech producer, meet the balking consumer, Sloan Management Review 36, No 2, 37-49.

[6] Dutta S. and A. Segev (1999), Business transformation on the Internet, European Management Journal 17, No 5, 466-476.

[7] Dutton W., P. Kovaric and C. Steinfield (1985), Computing in the home: A research paradigm, Computers and the Social Sciences 1, 5-18.

[8] Martin J A (1999), Typical PC buyer - revealed, [WWW-document], http://cnn.com /TECH/computing/9905/21/pcuser.idg, (21.6.1999)

[9] McFarlan F.W. and R.L. Nolan (1995), How to Manage an IT Outsourcing Alliance, Sloan Management Review 36, No 2, 9-23.

[10] Statistical office (1997) Nurmela J, Suomalaiset ja uusi tietotekniikka (Finnish persons and new IT), Katsauksia 1997/7, Tilastokeskus, Helsinki. p. 71

[11] Strauss A. and J. Corbin (1990), Basics of qualitative research - Grounded theory procedures and techniques, Sage Publications, Newbury Park Ca. 